\title{
Multidisciplinary Energy Assessment of Tertiary Buildings: Automated Geomatic Inspection, Building Information Modeling Reconstruction and Building Performance Simulation
}

\author{
Faustino Patiño-Cambeiro ${ }^{1, *}$, Guillermo Bastos ${ }^{2}$, Julia Armesto ${ }^{3}$ and Faustino Patiño-Barbeito ${ }^{2}$ \\ 1 Industrial Engineering School, University of Vigo, Rúa Maxwell, 36310 Vigo, Spain \\ 2 Industrial Engineering School, University of Vigo, Rúa Conde de Torrecedeira 86, 36208 Vigo, Spain; \\ inardesign.gbastos@uvigo.es (G.B.); fpatino@uvigo.es (F.P.-B.) \\ 3 Mining Engineering School, University of Vigo, Campus as Lagoas Marcosende, 36310 Vigo, Spain; \\ julia@uvigo.es \\ * Correspondence: faustinopc@uvigo.es; Tel.: +34-986-813-494
}

Academic Editor: Francesco Calise

Received: 27 March 2017; Accepted: 13 July 2017; Published: 19 July 2017

\begin{abstract}
There is an urgent need for energy efficiency in buildings within the European framework, considering its environmental implications, and Europe's energy dependence. Furthermore, the need for enhancing and increasing productivity in the building industry turns new technologies and building energy performance simulation environments into extremely interesting solutions towards rigorous analysis and decision making in renovation within acceptable risk levels. The present work describes a multidisciplinary approach for the estimation of the energy performance of an educational building. The research involved data acquisition with advanced geomatic tools, the development of an optimized building information model, and energy assessment in Building Performance Simulation (BPS) software. Interoperability issues were observed in the different steps of the process. The inspection and diagnostic phases were conducted in a timely, accurate manner thanks to automated data acquisition and subsequent analysis using Building Information Modeling based tools (BIM-based tools). Energy simulation was performed using Design Builder, and the results obtained were compared with those yielded by the official software tool established by Spanish regulations for energy certification. The discrepancies between the results of both programs have proven that the official software program is conservative in this sense. This may cause the depreciation of the assessed buildings.
\end{abstract}

Keywords: BIM; energy efficiency; BPS; building energy certification; design builder

\section{Introduction}

In the European Union, buildings accounted for $40 \%$ of total energy consumption and $36 \%$ of $\mathrm{CO}_{2}$ emissions in 2012 [1-3]. More specifically, non-residential buildings, which make up only $25 \%$ of the total European building stock, have an average energy consumption at least $40 \%$ higher than that of the residential sector [4]. The impact of the building sector in the energy balance, together with the current context of uncertainty regarding energy supplies for energy-deficient Europe, together with the renovated commitment towards climate change of the Paris Conference of the Parties (COP21) [5], have made the improvement of the energy efficiency of buildings a priority in the European agenda. Apart from the macroeconomic and environmental gains, promoting energy renovation of existing buildings by means of efficient construction techniques can also contribute to rehiring workforce in the building industry [6]. However, even though, in practice, the building stock is mostly obsolete 
and shows a great potential for improvement regarding energy performance in most EU countries, the annual renovation rate is estimated to be only $1 \%$ to $2.5 \%$ [1].

Any energy rehabilitation process of a given building starts with energy modeling [7], followed by the simulation of different active or passive solutions, and decision making [8], ending with the project execution. If properly executed, all these stages can lead to energy savings and emission reduction [9]. Large deviations between predictions and final results are frequent. In order to cope with this issue, energy models that accurately and faithfully represent the configuration and conditions of the buildings need to be developed. The simulation stage is therefore essential [10].

The energy model of a building involves 3D geometry, location (topographic orientation), local weather data, construction materials, thermal bridges, system characteristics, and general data (type of use, occupancy profile, etc.) [11]. All these data are to be compiled in the so-called building information model (BIM). The use of BIM-based tools is relatively widespread in the construction industry, and they are being increasingly required as mandatory management tools for official projects in several developed countries [12]. Furthermore, in the last years BIM tools have proven to have great potential for efficient management and energy optimization in building construction and renovation projects [13-15]. However, the use of BIM tools is still infrequent in the field of energy efficiency, and even more when it comes to modeling and renovating existing buildings.

The as-built BIM process, intended both for energy evaluation and general purposes, is commonly based on 2D-CAD drawings, which constitutes a time-consuming task. Moreover, in some cases, original drawings of existing buildings are obsolete because of subsequent refurbishments. In this case, hand-held devices like laser rangefinders can be used to obtain the characteristic dimensions of spaces in the building. Such manual procedures are time-consuming and depend upon the operator's skills. Geomatic technologies can represent a promising alternative. Thanks to remarkable advances achieved in the fields of device, electronics, and robot miniaturization over the last decades, geomatic technologies have gained unprecedented momentum. The usefulness of 3D laser scanning in the generation of 3D building information models in the fields of architecture, engineering and construction (AEC) has been noted in specialized literature [16,17]. 3D laser scanners provide very high acquisition rates, acceptable accuracy and significant savings in field work. These non-destructive, non-contact devices allow to collect geometric information from all sorts of facilities and structures, under construction or renovation, avoiding damage or modification [18,19]. Moreover, they have been used for integrated facilities management (IFM) regarding structural and stability assessment [20].

In the last years, laser scanners have evolved into mobile solutions. This implies the integration of laser devices, inertial units and Global Navigation Satellite System (GNSS) antenna. This kind of digitizing solutions are considerably widespread. Riegl (Horn, Austria), Optech (Ontario, ON, Canada), IGI Systems (Kreuztal, Germany) and Leica (Heerbrugg, Switzerland) are some of the most well-known manufacturers. However, mobile laser scanning systems suitable for indoor spaces are still scarce. The reason is that geolocalization is a challenging subject when it comes to GNSS-denied environments. Some devices are commercially available: iMS3D (VIAmetris, Louverné, France), Zebedee (CSIRO, Canberra, Australia), Scan Localizer (FARO, Lake Mary, FL, USA), and TIMMS (Trimble, Sunnyvale, CA, USA). This type of devices generate 3D point clouds of the as-built environments under analysis as described in [21,22]. However, most of them do not offer additional information that might be useful for energy evaluation purposes, such as thermograms or ambient data. An interesting contribution in this field is the multi-sensor approach described in [23], which enables the creation of 3D, thermal models. The review of thermographic inspections on buildings by Fox et al. [24] comprises a number of studies on the combination of this technology with unmanned aerial vehicles (UAV).

The 3D point clouds first obtained using laser-based modeling systems are not useful for BIM or energy modeling as a point-based structure. Parametrizing the 3D point cloud, structuring the parametric model in construction elements, and finally linking the elements with their surface and volumetric attributes is additionally required in this case. In the end, the point cloud can be transformed into a building information model. In this field, Volk et al. [7] reported significant progress regarding 
laser scanning solutions and 'scan-to-BIM' processes, but the automatic generation of semantically rich 3D models remains at early stage for commercial solutions.

Thermal zonification is another relevant step in the energy-modeling process. According to Picco et al. [25], simplifications in this specific task can introduce deviations up to $20 \%$ with respect to a detailed zonification. Different levels of detail are allowed in commercial software. The simpler tools assume single spaces, while more sophisticated ones (TRNSYS, Design Builder, etc.) allow a detailed thermal zonification on the basis of criteria such as occupancy profile topographic orientation, and number of stories, among others.

The detection of thermal bridges is also a critical stage. Inspections for detection of these features are usually carried out using hand-held thermographic cameras. Thermograms are taken when thermal anomalies are detected. The correct identification of the whole thermal bridges in the building depends on the skills and criteria of the operator. After inspection, the thermograms are usually stored in a single folder. Since no information regarding the location in the building of each thermogram is recorded, there is a risk of misallocation. In the last years, commercial thremographic devices have experienced some advances regarding miniaturization and triggering functionalities. This offers the possibility of integrating these devices with other sensors and/or automating the acquisition stage. The 3D scanning system described in [23] provides an example of this.

Once the energy model of a building under analysis is completed, the energy performance simulation is accomplished using specific software commonly known as BPS, Building Performance Analysis (BPA) or Building Energy Modeling (BEM) [26]. However, energy simulation tools, both for renovation or new construction, can still be improved by linking building information models and BPS tools [27]. The binomial BIM-BPS is currently under-exploited when it comes to maximizing energy efficiency of buildings, partly due to tool-interoperability issues. The combined use of BIM and BPS tools is even more limited in the case of existing buildings. In such cases, application is generally more complex due to the frequent lack of information regarding the building elements and the energy performance of electrical systems.

This work provides a multidisciplinary methodological approach for the estimation of energy performance in tertiary buildings, including data collection with advanced geomatic techniques, the development of an optimized building information model, and energy assessment. Energy simulation was carried out using Design Builder, a globally renowned energy-assessment software for buildings. This detailed and advanced evaluation was further compared with the official Spanish simulation tool in order to quantify deviations between both.

The present paper is structured as follows: the next section introduces BIM-BPS tools. The latest European regulations for the implementation of BIM-based tools and energy-saving measures for buildings are presented in Section 3. Section 4 describes the building that was chosen as the case study. Section 5 explains the procedure followed, which involved the inspection of the building, BIM and BPS energy assessment. Results and final discussion are given in Section 6, and conclusions are presented in Section 7.

\section{Background on BIM and BPS Tools}

BIM-based tools can play an essential role in construction productivity, both in renovation and new construction projects. Global productivity in the construction industry decreased by $25 \%$ between 1992 and 2007, causing a considerably lower productivity in comparison with other industrial processes in the same period $[27,28]$. BIM-based tools have a potential for improving productivity not only regarding general construction, but for energy-efficient design as well.

The most widely used BPS tools include Integrated Environmental Solutions-Virtual Environmental (IES-VE) [29], an integrated building simulation program which carries out energy analyses in different modules. All of these modules operate by means of a single energy model, which can be created in Revit or SketchUp. The QUick Energy Simulation Tool (eQUEST) combines a building creation wizard, an energy efficiency measure wizard, and a simulation engine based on the software Department of 
Energy of the USA-2 (DOE-2) [30]. Transient System Simulation (TRNSYS) is one of the most commonly used energy simulation tools for buildings and Heating, Ventilating, and Air Conditioning (HVAC) systems, including solar and geothermal systems. It has a modular structure too, and it works with open-source models, providing flexibility for adding new components developed in other tools [31]. Thermal Analysis Software (TAS) is an industry-leading BPS tool for thermal simulation of complex buildings. It has a good reputation among experts thanks to its detailed modeling and accurate prediction of energy consumption, $\mathrm{CO}_{2}$ emissions, operating costs and occupant comfort [32,33]. Lastly, Design Builder is a user-friendly graphic interface attached to the calculation engine EnergyPlus. It can be used throughout all the design stages. Among other things, it allows the calculation of energy use, the visualization of solar shading, the thermal simulation of naturally ventilated buildings, and the modeling of control aimed at savings in electric lighting [34].

EnergyPlus is one of the most accurate energy-simulation software programs. It was developed on the basis of DOE-2 and Building Loads Analysis and System Thermodynamics (BLAST) software programs, which in turn were created by the US Department of Energy (DOE) and the Department of Defense (DOD) [35]. EnergyPlus builds on the strengths of both of them, adding new calculation methods and features. It performs the modeling of energy flows of heating, cooling, lighting, and ventilation, as well as water usage. The integration of the thermal load simulation and the system response in the same step is one of the main improvements of EnergyPlus, providing a greater accuracy over DOE-2. Imbalances between both elements are reduced in the next step adjusting indoor thermal parameters [36,37].

The linking of BIM and BPS tools is an active field of research. Interoperability is essential to optimize energy simulation, both for renovation and new construction projects, as pointed out by Prada et al. [38]. They encountered problems while attempting to link a building information model which has been built using Revit in combination with the two BPS tools most widely used in the American continent-IES-VE and eQUEST simulators. Many authors have reported the inability to properly export some geometrical objects. Furthermore, ad-hoc modifications could not be translated into the BPS models. Nevertheless, some experiences have been successful in this area. See, for example; Jalaei et al. [39], who proposed a method to integrate Leadership in Energy and Environmental Design (LEED) certification for sustainable building and the combined use of BIM, BPS-Ecotect-and economic assessment. Choi et al. [40] developed a complete BPS environment which could be successfully linked from Revit and from ArchiCAD, yielding very similar results to those obtained using the renowned, free BPS software EnergyPlus.

An example of the application of this technology in the case of existing buildings can be found in the work of Gourlis et al. [41], who built an as-built building information model of the envelope of a historic industrial building and exported it to a BPS environment. Furthermore, they provided a retrospective on similar studies on industrial buildings. In their review of scientific publications, Ilter et al. [42] noted that BIM-BPS analysis is unusual in renovation and maintenance actions. They highlight the need to improve interoperability. In 2016, the review by Khaddaj et al. [16] combined sustainability criteria with the BIM approach in the field of existing buildings. They concluded that BIM was still too underdeveloped for its application in renovation projects, mainly because of data uncertainty, and the need for automation of data acquisition.

Finally, the most widespread formats for linking BIM and BPS will be commented upon. Green building extensible markup language $\left({ }^{*} \mathrm{gbxml}\right)$ and industrial foundation classes $\left({ }^{*} \mathrm{ifc}\right)$ are the most common ones. The advantage of * gbxml over *ifc is that it is simpler, and easier to assimilate by BPS. The strength of *ifc is that it is the only ISO standard in the field [43], which has made it the prevailing format for BIM. *ifc format allows to overlap several types of information layers [44].

New schemes to facilitate BIM-BPS communication are under development. A good example is provided by Jeong et al. [45], who presented an object-based format, developed with object-based programming that facilitates the recognition of space boundaries. Their algorithm enables the use of a building information model in BPS software without export/import process. 


\section{European Regulatory Framework on Energy Efficiency of Buildings}

According to Chalmers et al. [46], there is a $50 \%$ to $90 \%$ energy-saving potential, both for new and existing buildings, in all EU Member States [47]. In order to encourage developments in this area, the European Parliament published Directive 2010/31/EU on the Energy Performance of Buildings (EPBD) [48], which became applicable in 2012. The Directive meant a major leap in the energy performance requirements for buildings, since it invites the Member States to develop a methodology for the calculation of energy efficiency, as well as to lay down minimum requirements in this direction, and to create an energy certification program. It aims at the energy-efficient near Zero-Energy Building as an objective [49]. In the global scene, the term Net Zero-Energy Building is commonly used, along with the more ambitious concept of Positive Energy Building [50].

EPBD defines the energy performance of a building as the energy demand associated with its typical use. This includes, among others, heating, cooling, ventilation, Domestic Hot Water (DHW), and lighting. According to the Commission Delegated Regulation 244/2012 [51], the calculation of the energy performance must start with energy needs for heating and cooling, and finish with net primary energy. This is, moving from the energy demand towards the energy source.

The Directive also introduces a certification system for guiding users and buyers on energy consumption for buildings. The subsequent Directive 2012/27/EU [52] systematically stresses the need to promote building sustainability through the refurbishment of the building stock. Since most of the EU stock is obsolete in terms of energy performance, this option is more effective compared to building new efficient housing.

The European guidelines provided by EPBD were transposed into Spanish law through Royal Decree 235/2013 [53]. This Decree includes a basic procedure for the certification of energy performance for both new and existing buildings. The certificate provides a label which specifies the building's energy consumption and $\mathrm{CO}_{2}$ emissions, together with a letter which stands for the corresponding energy class.

In Spain, the convergence of energy certification under the HE Basic Document of the Spanish Technical Code of Building (CTE-DB-HE) [54] and the Regulation for Thermal Systems in Buildings (RITE) [55] — both of which were updated in 2013 — forced the revision of the certification procedure. Directive 2012/27/EU was partially transposed into Royal Decree 56/2016 [56]. One of its aims is to promote the training of professionals in the areas of energy efficiency and audits. The simplified tool for existing buildings CE3X, together with the unified tool Limitation of Energy Demand-Calification Energy (LIDER-CALENER), for all types of buildings-both planned and existing - [57], are the most widely-used, authorized tools for energy certification for service buildings in Spain. An additional authorization of the Spanish Ministry of Industry, Energy, Tourism and Ministry of Public Works is required for using other tools. This constitutes a barrier to other programs. In fact, to this date, CE3X has been used in $98 \%$ of all energy certifications in Spain [58]. For this reason, it was decided to compare it with the commercially available energy modeling tool Design Builder, which includes the calculation engine EnergyPlus.

CE3 $x$ was designed for facilitating energy certification. It uses simplifications of the requested data, the thermal behavior modeling of the building and the calculation engine, which, in turn, is based on the correlations and approximations carried out by LIDER-CALENER. Such simplifications are conservative, yielding more "pessimistic" results compared to the real values [59].

The energy certification system shows how building technologies are being developed faster than building codes. This gap could be reduced if more freedom was allowed in the field of energy performance certification, and European regulations were more flexible in this sense. In twelve Member States, both official and commercial software are accepted. In other twelve Member States, only a commercial software is provided by law. Validation for the use of the chosen software is not even required in five of those countries [60].

Finally, at the European level, Directive 2014/24/EU [61] on public procurement stresses the need to promote "electronic means of information and communication" in procurement processes for works, 
services or supplies, by September 2018. More specifically, it invites Member States to "require the use of specific electronic tools, such as of building information electronic modeling tools". Some countries have already taken action in this sense. BIM framework is already mandatory in the UK and Nordic countries-at least for the procurement of public works. In the case of Spain, the requirement for BIM framework has been scheduled for December 2018 in buildings, and July 2019 for infrastructures [62].

\section{Case Study}

The building chosen for this study is the Forest Engineering School (in Spanish Escuela de Ingeniería Forestal, hereinafter EIF) of Pontevedra. It is located virtually at sea level on the Atlantic coast of Spain. It has four stories with a total area of $8504 \mathrm{~m}^{2}$. Its location and general appearance can be observed in Figure 1. No renovations have been carried out on the building envelope or energy systems since it was built in 1994. The building code applicable at the time of its design was NBE-CT-79 [63]. The only energy-saving measure included in this regulation is the minimum thermal insulation of the envelope.

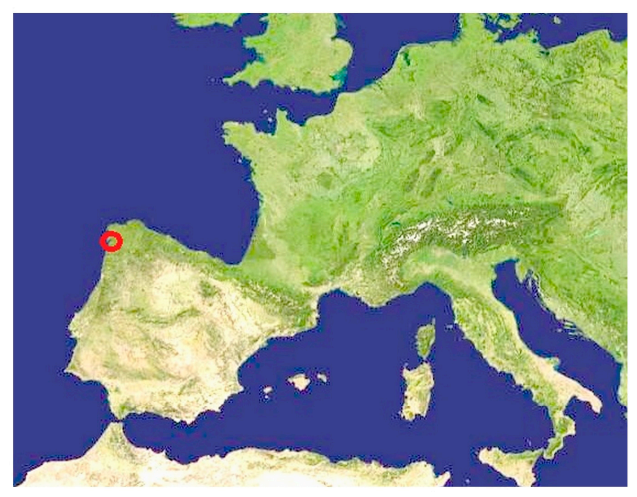

(a)

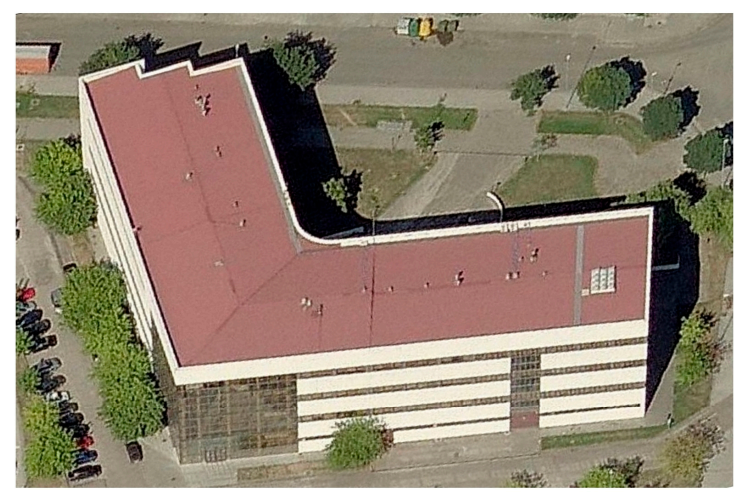

(b)

Figure 1. (a) Location of Pontevedra (source: www.zonu.com); (b) Satellite photograph of Pontevedra Forest Engineering School (source: www.bing.com/maps).

The heating system is powered by two diesel oil boilers that have been operating since the EIF was established in 1994. Most of the indoor spaces are heated by radiators. The halls of the central area, two laboratories and the conference hall are equipped with fan-coils. The cafeteria is the only area that requires the use of DHW, with an estimated demand of $180 \mathrm{~L} /$ day. The main characteristics of the systems are shown in Table 1. As it can be observed, the contribution of lighting to the generated heat is relevant, as it is usual in the case of service buildings. The building has a low occupancy profile—only 258 students. Opening hours are 8:30 A.M. to 9:30 P.M., Monday to Friday.

Table 1. Main characteristics of the energy systems.

\begin{tabular}{ccc}
\hline Energy Systems & Power & Efficiency \\
\hline Two diesel oil boilers & $2 \times 291 \mathrm{~kW}$ & Seasonal efficiency $85 \%$ \\
Fan-coils & $5.2 \mathrm{~kW}$ & Estimated efficiency 92\% \\
Electric heater for DHW & $10 \mathrm{~kW}$ & Seasonal efficiency $90 \%$ \\
Indoor lighting & $103.8 \mathrm{~kW}$ & Mean efficiency $55 \%$ \\
\hline
\end{tabular}

\section{Methodology}

The procedure followed for measuring the energy performance of the building under study is summarized in Figure 2. The energy inspection of geometric 3D data gathering data was performed using an Indoor Multi-Sensor Acquisition System (IMAS). Once the 3D building information model was built up in Revit on the base of the 3D point cloud, the model was transferred into Design Builder. 
The energy model was completed with thermal bridges detected in the IMAS inspection, and thermal zonification was decided considering topographic orientation, building floors, occupancy profile and the 2D comfort maps derived from the IMAS inspection. Subsequently, the energy performance was run. An analogous simulation process was carried out in CE3X. Eventually, a comparison of the results was carried out.

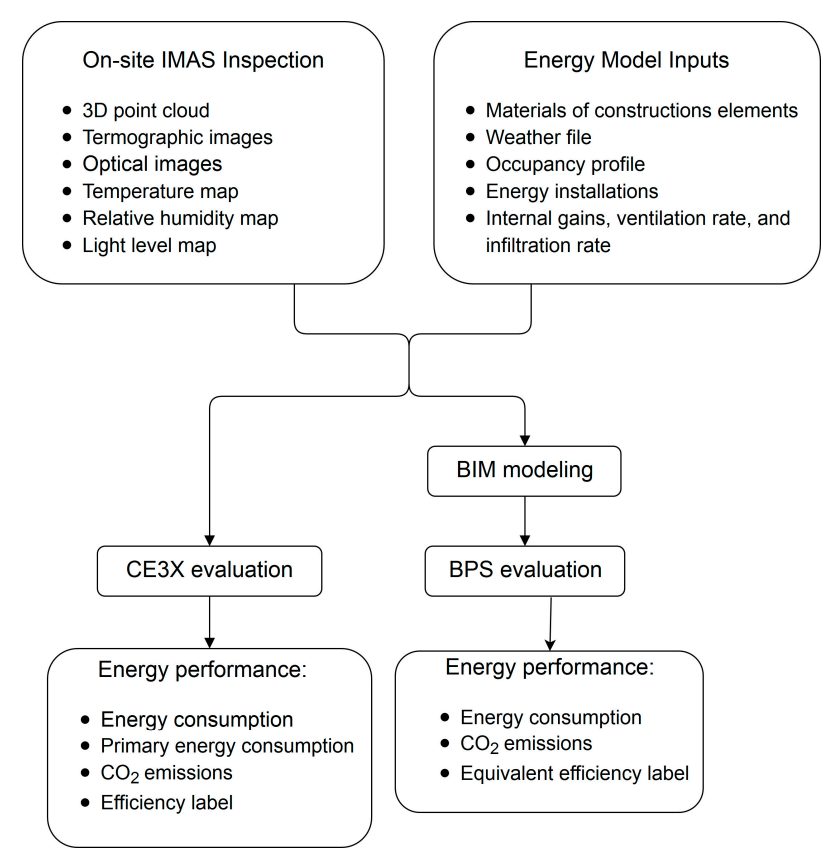

Figure 2. Methodology flow chart: from on-site data acquisition to evaluation of energy performance.

\subsection{Data Collection}

In order to obtain the necessary information regarding the 3D geometry of the partitions and their characteristics, as well as some other useful information for a proper energy modeling, an on-site data collection was carried out with the IMAS [64]. The wheeled robot was driven by an operator along the building. Once it was turned on and in motion, it automatically recorded all the data. IMAS operates Simultaneous Localization and Mapping (SLAM) algorithms to perform self-localization in real time in GNSS-denied environments. It is equipped with laser sensors for 3D modeling, thermographic and optical cameras, and comfort sensors, as it is described in [64]. They all are synchronously triggered by the main central computer, and the output data (images, laser profiles, temperature and humidity values) are time-stamped. As a result, a 3D-point cloud of the indoor space was generated in real time. 2D maps reflecting the temperature and humidity gradients along the inspection path were additionally obtained, and eventually georeferenced thermograms were created.

A navigation interface based on the cross-platform application framework Qt was developed for the ex-situ inspection of the gathered data [65]. Figure 3 shows an IMAS photograph, together with a screen capture of the ex-situ navigation interface. This interface allows an ex-situ analysis of the inspection path. The data recorded at different points of the inspection path are loaded simultaneously, being the point cloud reprojected to a single-point convergent perspective. The images and point cloud are editable to perform measurements. As a result, the user has an immersive point of view. Every feature of an instant thermography can be easily identified thanks to the visible image, and immediately measured in the 3D point cloud. This enables the identification of thermal insulation and waterproofing problems as thermal bridges, and their dimensional characterization.

The verification of the 3D-models obtained using the IMAS robot is described in Armesto et al. [64]. It was conducted by comparison with the point cloud obtained by a terrestrial laser scanning system (TLS). The equipment used for this purpose was a phased based device, a FARO 
Focus3D, which provides a nominal accuracy of $\pm 2 \mathrm{~mm}$ at $25 \mathrm{~m}$ distance. Dimensional characteristics such as length, height and width of halls and rooms were measured in both data sets. The resulting errors are shown in Table 2. Further, a point-to-point comparison was performed. The mean of distances between points is $0.0953 \mathrm{~m}$, and the standard deviation $0.0928 \mathrm{~m}$. Details are provided in [64].

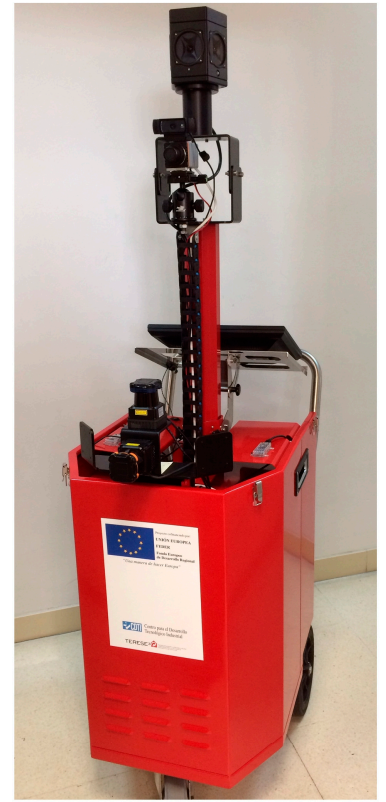

(a)

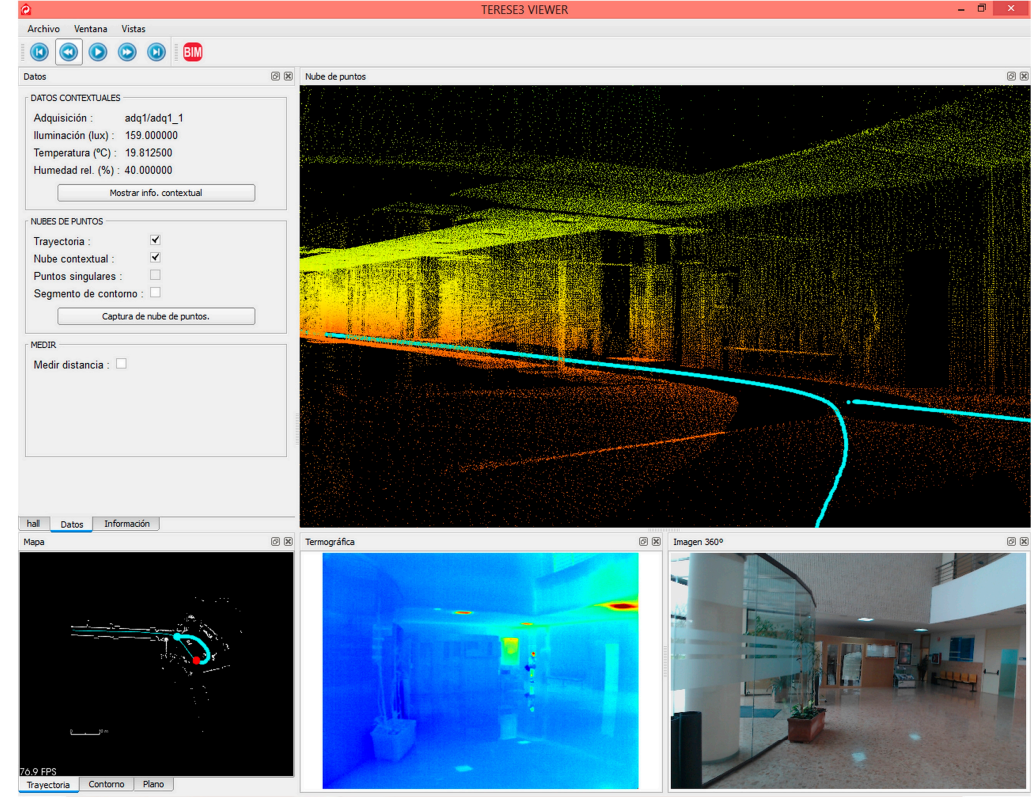

(b)

Figure 3. IMAS system: (a) Picture of the IMAS robot; (b) Appearance of the generated maps.

Table 2. Quality evaluation of the IMAS 3D model through comparison with a TLS FARO Focus3D [64].

\begin{tabular}{ccccc}
\hline & IMIS (m) & FARO $(\mathbf{m})$ & $\varepsilon \mathbf{~ ( m )}$ & $\mathcal{E}_{\mathbf{r}} \mathbf{~ ( \% )}$ \\
\hline Corridor length & 31.577 & 31.527 & 0.050 & $0.16 \%$ \\
Corridor height & 3.009 & 3.000 & 0.009 & $0.30 \%$ \\
Corridor width & 3.022 & 3.018 & 0.004 & $0.13 \%$ \\
Hall length & 12.651 & 12.628 & 0.023 & $0.18 \%$ \\
Small corridor length & 14.492 & 14.427 & 0.065 & $0.45 \%$ \\
Room length & 14.232 & 14.120 & 0.112 & $0.79 \%$ \\
\hline
\end{tabular}

The specifications of the construction materials of the building under study and administrative data (date of construction, occupancy profile, type of use), were extracted from the EIF original project document. The characteristics of the electrical systems were also derived from the data contained in the construction project of the building. Their maintenance state was verified through an in-situ inspection.

\subsection{Development of the Building Information Model}

The initial modeling of the building was done using Revit, one of the most commonly used BIM programs in architecture, engineering and construction worldwide [66]. The IMAS 3D-point cloud can be obtained in *ascii and *las formats. Both of them can be converted into *pcg format, which is compatible with Revit. Previously, a decimation must be performed in a 3D-mesh editor. The openings of the building were added to the Revit library, together with a 30-cm-wide standard partition for all façades. Once the interior rooms were created based on the 3D point cloud, they were assigned a three-dimensional space in Revit, to be subsequently used with Design Builder. The definition of $3 \mathrm{D}$ zones was performed by merging the rooms that have the same occupancy profile. The different rooms of each floor, limited by their interior partitions, are shown in Figure 4 . A total of 45 rooms were set to be simulated in Design Builder. 


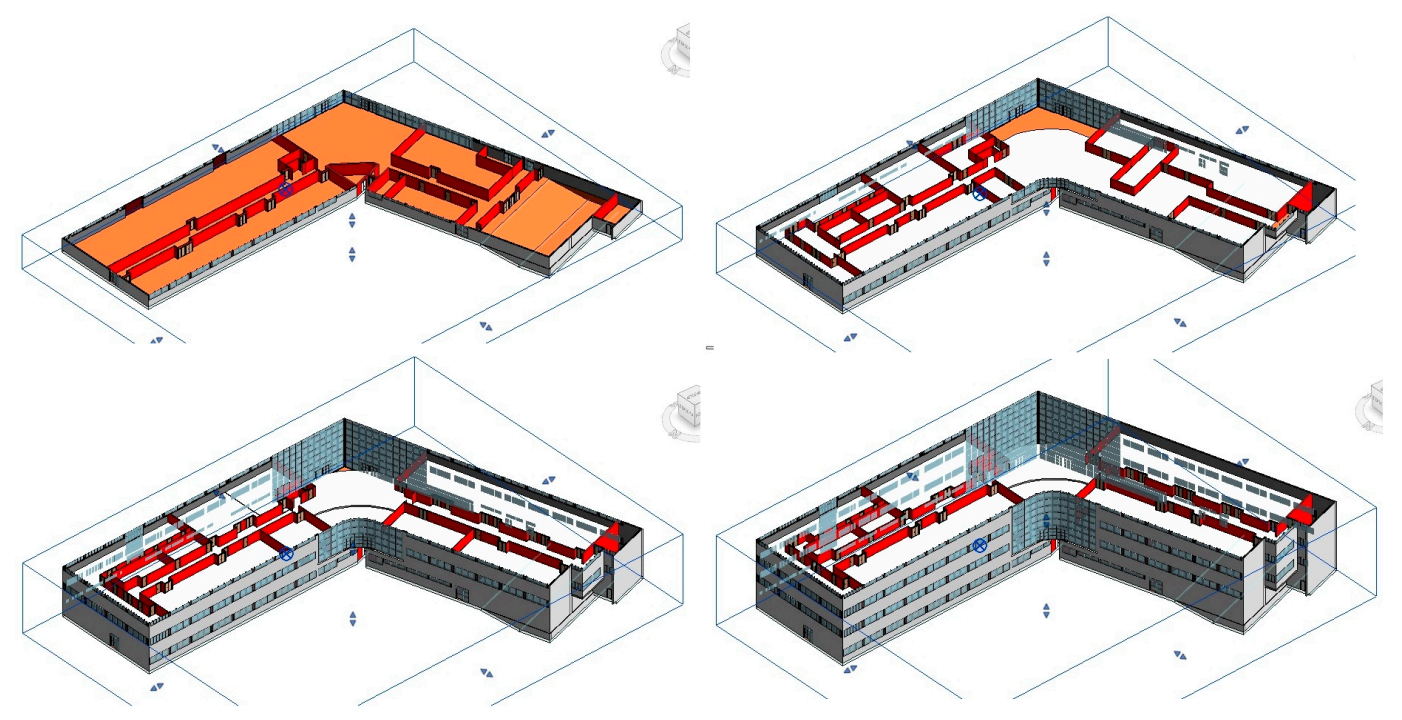

Figure 4. Rooms for each floor of the building limited by interior partitions.

Finally, the model was assigned an orientation with respect to North. Figure 5 shows the final model. Using the point cloud provided after the robot-assisted inspection, a technician with advanced skills in the use of Revit needed three days to construct the building information model. In turn, this step took around seven days using the CAD drawings of the building-the traditional method.

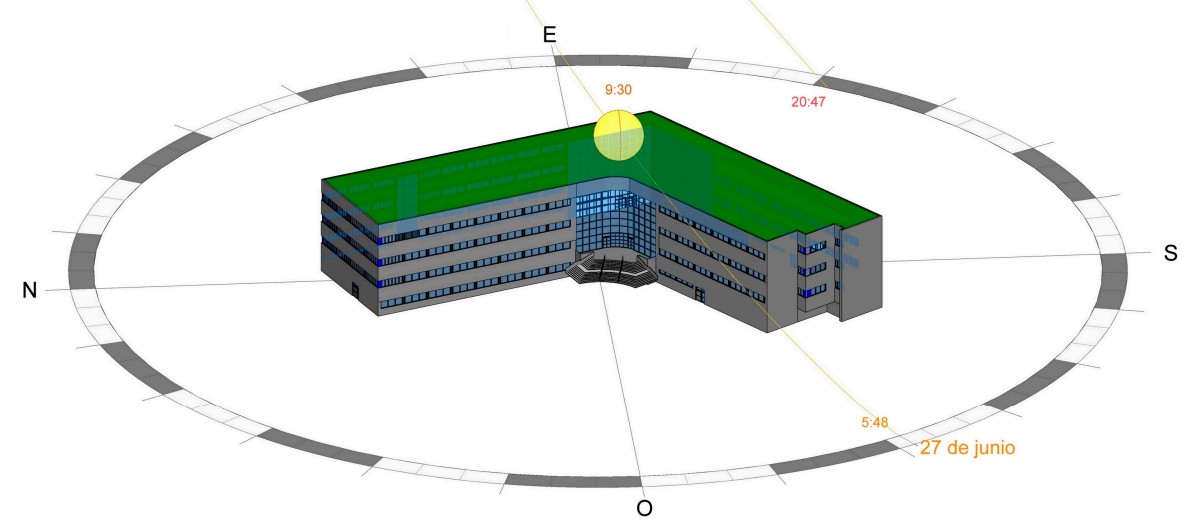

Figure 5. Revit model of the EIF (northwest façade).

All the material properties were extracted from the Component Catalogue of the Spanish CTE [67].

\subsection{Energy Assessment in Official Software CE3X}

Data required by CE3X can be classified into four categories:

- Administrative data

Data of the building identification, location and customer.

- Basic data of the building

General information about the building, i.e., year of construction, intensity of use, climate zone, habitable volume, demand for DHW, and ventilation rate. They strongly influence the final energy rating. 
- Thermal envelopev

A 3D model of the building is not built as such. Instead, general dimensions are introduced. In this study case, four façades were created for the four main orientations of the building. The data entered were total surface, the average height of the four stories, openings, and thermal bridges. The same procedure was followed for defining the floor and the roofs. The confined spaces under the roof and on the ground are defined separately. Again, only their general dimensions and characteristics are required. All the dimensions necessary to define partitions, openings, and thermal bridges were taken from the building information model in Revit. The material for each element is selected, and CE3X takes its thermal characteristics from the CTE-DB-HE [54].

- Energy systems

The characteristics of the different systems described in Section 3-nominal and seasonal performance, installed capacity-were entered.

After the introduction of the aforementioned information, simulation was started. The results obtained are shown in Table 3. The energy demand of a building is the energy needed to maintain a comfort environment inside the building, and is mainly obtained by heating and cooling. It is primarily determined by the materials and the shape of the building, the immediate building surroundings, the climate, and the occupancy profile. The final energy consumption is the actual energy consumed at the user level. It is derived from the energy demand and the efficiency of the energy systems. The lighting system has a relevant share in the energy needs of service buildings, and constitutes a significant thermal gain. The final energy consumption for lighting is calculated directly from the specifications of the lighting system and the occupancy profile. The primary energy consumption is the sum of the final energy consumption and the extraction, transformation and distribution losses. It is obtained by applying primary energy factors [48] to the final energy consumption. $\mathrm{CO}_{2}$ emissions, estimated using emission factors and primary energy factors published by the Spanish Ministry of Industry, Energy and Tourism, are presented as well [68]. As it was stated in Section 3, the EPBD establishes the use of the energy need to define the energy performance of a building. A letter standing for the level of energy efficiency corresponding to the energy certificate, ranging from " $\mathrm{A}$ " (maximum efficiency) to " $G$ " (minimum efficiency), is placed after the obtained values. The threshold values for the different categories depend on the climate zone, occupancy, etc., together with the calculation methodology for these values, have been provided by the Spanish Institute for Energy Diversification and Savings (IDAE) [69].

Table 3. Energy consumption parameters obtained by Design Builder and CE3X, and the $\mathrm{CO}_{2}$ emissions derived from them. The letters represent the level of the energy efficiency according to CE3X.

\begin{tabular}{ccccc}
\hline & Energy System & CE3X & Design Builder & Deviation of CE3X (\%) \\
\hline Energy demand & Heating & $55.30-\mathrm{F}$ & $44.96-\mathrm{E}$ & 23.0 \\
$\left(\mathrm{kWh} / \mathrm{m}^{2} /\right.$ year $)$ & Cooling & $18.00-\mathrm{C}$ & $2.30-\mathrm{A}$ & 682.6 \\
& DHW & 0.40 & 0.44 & -9.1 \\
\hline & Heating & 65.05 & 52.89 & 23.0 \\
Final energy consumption & Cooling & 9.00 & 1.15 & 682.6 \\
$\left(\mathrm{kWh} / \mathrm{m}^{2} /\right.$ year) & DHW & 0.45 & 0.49 & -8.1 \\
& Illumination & 43.32 & 43.32 & 0 \\
Primary energy consumption & Heating & 76.74 & 62.51 & 22.8 \\
$\left(\mathrm{kWh} / \mathrm{m}^{2} /\right.$ year $)$ & Cooling & 21.31 & 2.72 & 683.4 \\
& DHW & 1.07 & 1.18 & -9.3 \\
$\mathrm{CO}_{2}$ emissions & Illumination & 102.60 & 102.60 & 0 \\
$\left(\mathrm{~kg} \mathrm{CO}_{2} / \mathrm{m}^{2} /\right.$ year $)$ & Heating & 20.24 & 16.45 & 23.2 \\
& Cooling & 2.97 & 0.38 & 681.6 \\
\hline & DHW & 0.15 & 0.16 & -6.2 \\
\hline
\end{tabular}




\subsection{Energy Assessment in Design Builder BPS}

An interoperability test between Revit and Design Builder was performed using *gbxml format, including different elements: openings, walls, floors, ceilings, etc. The insulation characteristics were specified, together with the values for transmittance, reflectivity and conductivity, among others. Eventually, the export of the Revit model was not successful, as a considerable amount of data was lost in the process:

- A great amount of openings disappeared after importing the *gbxml model. In order to achieve a complete, smooth import of the model it was necessary to slightly increase the separation between the openings.

- Partitions were not properly exported, either. It was necessary to redefine them. Particular roof elements—a skylight and the central part of the roof-had to be reconstructed, too.

Consequently, the characteristics were defined again in Design Builder for every building element. The correction of the model resulted in the development of the envelope, the interior partitions, and the thermal bridges. Subsequently, the influence of the weather on the buildings was introduced through a weather file. Design Builder includes files for numerous Spanish and worldwide cities. Nevertheless, the weather file used was the same as in CE3X, in order to allow the comparison of results obtained using Design Builder and CE3X. According to the Basic Document HE on Energy Saving from the Spanish Technical Building Code, the EIF is located in climate zone C1. The file was downloaded in *met format from the web of the Spanish Ministry of Industry, Energy and Tourism [57] and converted to *epw format to allow its use in Energy Plus.

Design Builder sets an occupancy profile containing features such as schedules for occupancy, heating and cooling demand, equipment usage and lighting, among others, which are assigned to each space by default. The same occupancy profile entered in CE3X was adopted in order ensure that the starting conditions of the simulation are the same in both programs. It corresponds to the "non-residential/low intensity" profile from the Basic Document HE [54]. This document provides a table with the operation schedules of the different energy-generating or consuming elements, as shown in Table 4. On this basis, three operation schedules for the energy sources of the building were created: heating and cooling, internal gains and ventilation.

Table 4. Occupancy profile: non-residential, low intensity (12 h) [54].

\begin{tabular}{cc}
\hline & Working Days \\
\hline Time slot $(24 \mathrm{~h})$ & $7-14,17-20$ \\
Cooling set point temperature $\left({ }^{\circ} \mathrm{C}\right)$ & 25 \\
Heating set point temperature $\left({ }^{\circ} \mathrm{C}\right)$ & 20 \\
Sensible heat due to users $\left(\mathrm{W} / \mathrm{m}^{2}\right)$ & 2.00 \\
Latent heat due to users $\left(\mathrm{W} / \mathrm{m}^{2}\right)$ & 1.26 \\
Illumination $(\%)$ & 100 \\
Equipment $\left(\mathrm{W} / \mathrm{m}^{2}\right)$ & 1.50 \\
Ventilation $(\%)$ & 100 \\
\hline
\end{tabular}

Internal gains were set through a single $16.97 \mathrm{~W} / \mathrm{m}^{2}[54,55]$ total gain during the occupancy schedule of the building to enable the comparison of the results obtained by Design Builder and CE3X. The ventilation rate was 0.8 air changes per hour. The infiltration rate was provided in the list of recognized documents. It was calculated from the general characteristics of the envelope and the openings using the online application of Aurea Consulting [70], resulting in 0.17 air changes per hour.

The values of conductivity, specific heat and density of each material were taken from the Component Catalogue of the Spanish CTE [67] for the definition of the materials of the partitions. Since the values of the different absorptances and roughness are not indicated in the CTE, the default values from Design Builder were used. After that, the different types of partitions could be assigned to the 3D 
model. EnergyPlus has six internal-convection and seven external-convection algorithms. In order to proceed as in CTE, the Chartered Institution of Building Services Engineers (CIBSE) algorithm was selected for both types of convection. This algorithm adopts constant heat coefficients.

After this information was introduced, the simulation was run. Figure 6 represents the energy demand for the resulting heating and cooling. The periodic valleys correspond to weekends, when the EIF is closed. The thermal inertia of the building usually leads to spikes in the first days of the week. The other data related to energy assessment are shown in Table 3. They were calculated from the values obtained by Design Builder and using the emission and primary energy conversion factors provided by the Spanish RITE [55].

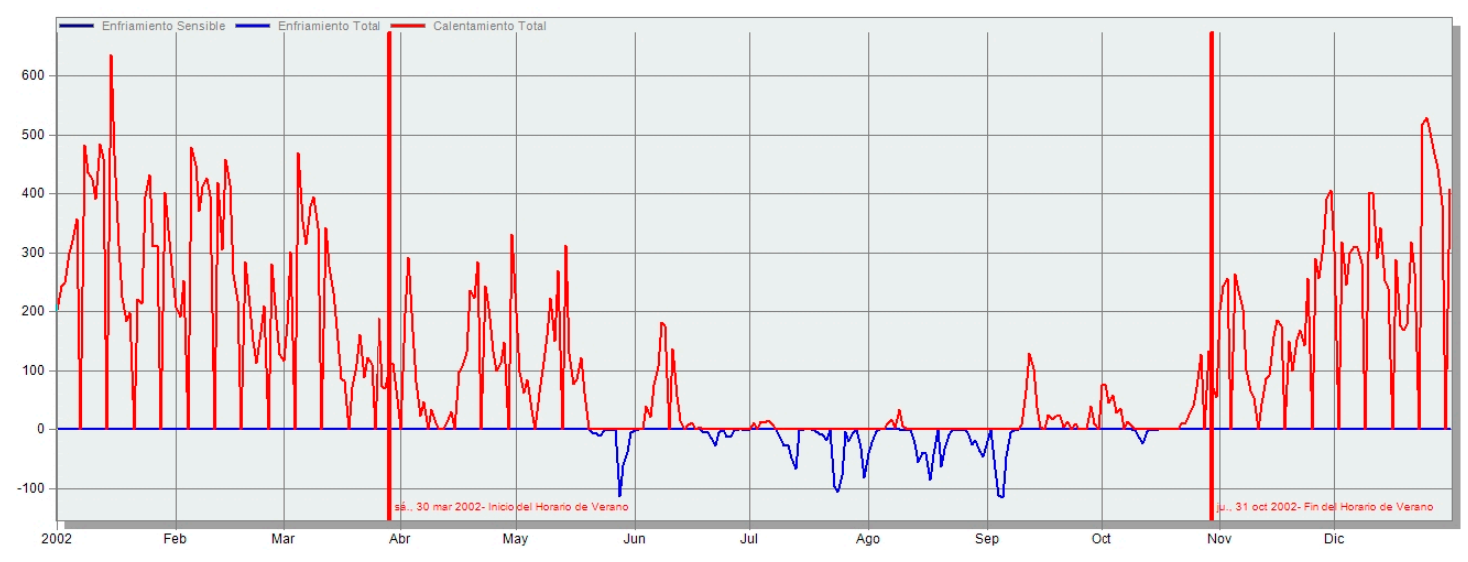

Figure 6. Heating demand in kilowatts calculated over a year.

\section{Discussion of Results}

With regard to the first phase of the process, it must be noted that the inspection of the building was performed automatically, and lasted only for a few hours. IMAS enabled the automatic 3D digital reconstruction. The building under study was modeled according to its as-built status, including all the modifications undergone by the interior partitions. Furthermore, the use of the IMAS facilitated the identification and characterization of thermal bridges, as well as the as-built status of the partitions, and the comfort conditions. Thanks to this data acquisition system, energy modeling times could be drastically reduced. Moreover, in line with the BIM philosophy, all the information gathered by the robot was stored together with the technical, legal and administrative documentation of the building. Such documents are nowadays evolving from printed to digital format.

The information collected by the IMAS as a point cloud, thermographic images, optical images, and maps of comfort variables, together with the data extracted from the document of the original project, allowed the development of a realistic, as-built building information model in Revit. Nevertheless, this is not an automatic process-it requires a careful manual operation.

Revit-Design Builder interoperability proved to be insufficient. Identifying and handling incorrectly defined elements is complex and time-consuming.

The comparison of the energy simulation results obtained using Design Builder and CE3X shows major differences both for heating and cooling demand, as it can be seen in Table 3. Although all input variables were analogously set for both environments Design Builder yielded 44.96 and $2.3 \mathrm{kWh} / \mathrm{m}^{2} /$ year for heating and cooling, respectively. In the case of CE3X, results were 55.3 and $18 \mathrm{kWh} / \mathrm{m}^{2} /$ year. Figure 7 compares the basic parameters obtained by both programs. Considering the demand derived from heating - the most energy-consuming system-, the energy class for this building according to the Spanish scale would be " $\mathrm{E}$ " for Design Builder, and " $\mathrm{F}$ " for CE3X.

As it can be seen in Table 3, CE3X estimated a 23\% higher heating demand compared to that yielded by Design Builder. Greater differences (up to 683\%) can be observed in cooling. These differences have been caused by the multiple conservative simplifications performed by CE3X. Such simplifications 
shift the results towards the low efficiency side. The reason for the extremely high difference in cooling demand is probably the definition of 3D-thermal zones in the geometric model. The Design Builder-simulated model uses the reconstructed building information 3D-model, which was divided into a total of 45 thermal zones. CE3X, in turn, considers a single space, and drastically simplifies the building envelope-only the basic dimensions, the composition of the partitions, and their orientation are introduced.

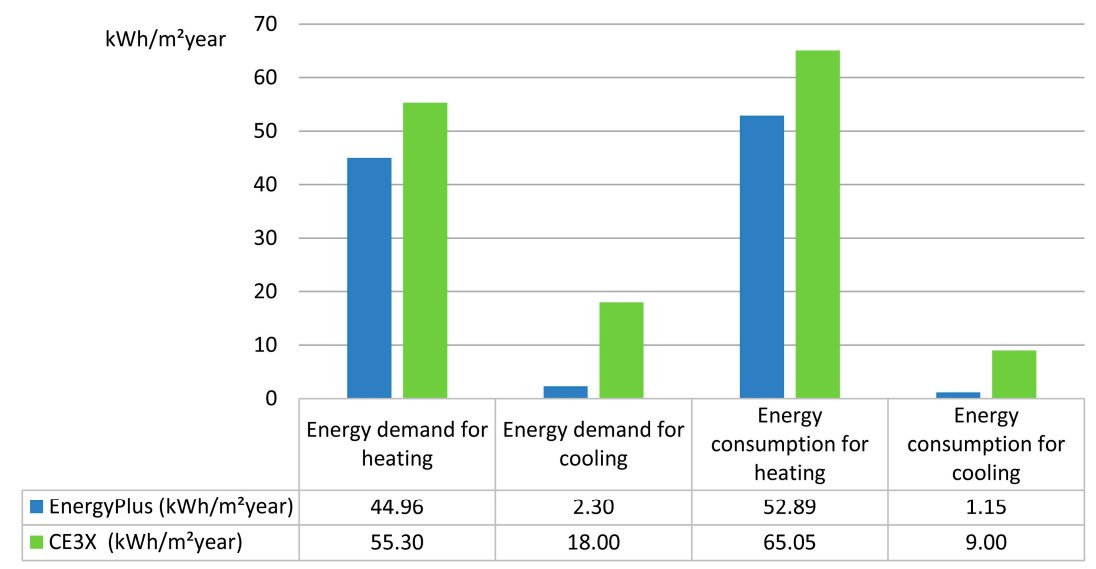

Figure 7. Overview of the building's efficiency according to EnergyPlus (Design Builder) and CE3X.

Such simplifications during modeling—especially the definition of thermal zones—had a decisive impact on the energy evaluation of the building. Since this tool does not distinguish between different floors or thermal zones, the glassed wall in the northwest and southeast façades affected the whole volume of the building. The IMAS robot constitutes a helpful tool in this sense. The provided instantaneous comfort maps can be used to discard or validate a zonification proposal in real time.

A secondary reason for the lower efficiency calculated by CE3X is the different level of development of both calculation engines. CE3X is based on simplified calculations from LIDER-CALENER, which is, in turn, based on DOE-2 software, developed in the 1980s. This program has not been updated for more than a decade, whereas EnergyPlus is still regularly updated.

\section{Conclusions}

The aim of this work is to present an instrument and a methodological procedure for assessing the energy performance of tertiary buildings. This methodology comprises the inspection of the case study building using a multi-sensor robot, which registers the geometric, thermal and comfort characteristics. The geometry is saved as a 3D-point cloud, which can be converted in a 3D-model by Revit. Subsequently, the energy performance of this model is calculated using Design Builder. In our study, the same calculation was performed in CE3X, a simplified tool commonly used in Spain, whose use is authorized for the energy performance certification process. Finally, the divergence between both programs was analyzed.

The use of an automated robot as a base for the development of a building information model allowed to minimize the dimensional errors and the data acquisition time. Furthermore, it provided geolocalized thermographies and comfort variables. As a result, the thermal bridges could be identified in their correct position within the building and dimensionally characterized. This methodology resulted in faster in-situ inspection and office analysis, and it increased the amount of information gathered, as well as its reliability.

The described process has shown that tool interoperability still constitutes a significant barrier. Geomatic technologies are highly productive when it comes to generating geometrical data, detecting thermal bridges and measuring comfort data. Nevertheless, developing as-built building information models implies an extensive manual editing. Moreover, BPS systems prevent a full data import. 
Time-consuming and costly model editing seriously compromises overall productivity. The use of Open BIM formats such as ${ }^{*} \mathrm{gbxml},{ }^{*} \mathrm{ifc}$, or ${ }^{*}$ ifcxml constitutes a future research line.

The comparison of CE3X with Design Builder revealed a high degree of divergence. In certain type of façades systems like those of the analyzed building the impact of considering no thermal zonification is very significant. Since the official software has shown to be highly conservative in the study case, authors remark the need to use an alternative program to support any decision-making process regarding energy rehabilitation. The conservativeness of the calculated efficiency may lower the value of appraised buildings, and could lead to erroneous decision-making in the real estate market or at energy efficiency renovation planning.

In view of the successful acquisition of the geometric data of the building through the IMAS robot, the development of software towards the automatic conversion of the 3D-point cloud into a 3D geometric model within the BIM framework represents a promising future line. The precision of the energy performance calculation of existing buildings is another trend in research. Accuracy can be improved by automating the acquisition of the actual energy performance data through the installation of sensors in the primary energy network, as well as in the indoor and the outdoor environments of the building.

Acknowledgments: The authors would like to thank the Ministerio de Economía y Competitividad and the Centro para el Desarrollo Tecnológico Industrial (Government of Spain) for the financial support given through the ITC-20151012 (Build 3D-Print) project, co-funded by the European Regional Development Fund. Further, the authors would like to thank the student Luis Gandarela Campos, from the University of Vigo, for his contribution in some technical computations.

Author Contributions: Julia Armesto and Faustino Patiño Cambeiro carried out the on-site inspection with the IMAS robot and the BIM process; Guillermo Bastos and Faustino Patiño Barbeito performed the calculations in Design Builder y CE3X and the further analyses. All the authors have contributed equally to the manuscript writing.

Conflicts of Interest: The authors declare no conflict of interest.

\section{References}

1. D'Agostino, D.; Zangheri, P.; Castellazzi, L. Towards nearly zero energy buildings in Europe: A focus on retrofit in non-residential buildings. Energies 2017, 10. [CrossRef]

2. Terés-Zubiaga, J.; Campos-Celador, A.; González-Pino, I.; Escudero-Revilla, C. Energy and economic assessment of the envelope retrofitting in residential buildings in Northern Spain. Energy Build. 2015, 86, 194-202. [CrossRef]

3. Aïssani, A.; Chateauneuf, A.; Fontaine, J.-P.; Audebert, P. Cost model for optimum thicknesses of insulated walls considering indirect impacts and uncertainties. Energy Build. 2014, 84, 21-32. [CrossRef]

4. Builidngs Performance Institute Europe (BPIE). Europe's Buildings under the Microscope. A Country-by-Country Review of the Energy Performance of Buildings; BPIE: Brussels, Belgium, 2011. Available online: http:/ /bpie.eu/ wp-content/uploads/2015/10/HR_EU_B_under_microscope_study.pdf (accessed on 27 February 2017).

5. United Nations. Reports-Addendum Part Two: Action Taken by the Conference of the Parties. In Proceedings of the Confertence of the Parties on Its Twenty-First Session, Paris, France, 30 November-13 December 2015. Available online: http://unfccc.int/resource/docs/2015/cop21/eng/10a02.pdf (accessed on 27 February 2017).

6. Meijer, F.; Visscher, H. Upgrading energy efficient housing and creating jobs: It works both ways. Open House Int. 2014, 39, 34-40.

7. Volk, R.; Stengel, J.; Schultmann, F. Building Information Modeling (BIM) for existing buildings-Literature review and future needs. Autom. Constr. 2014, 38, 109-127. [CrossRef]

8. Ryan, E.M.; Sanquist, T.F. Validation of building energy modeling tools under idealized and realistic conditions. Energy Build. 2012, 47, 375-382. [CrossRef]

9. Stadel, A.; Eboli, J.; Ryberg, A.; Mitchell, J.; Spatari, S. Intelligent sustainable design: Integration of carbon accounting and Building Information Modeling. J. Prof. Issues Eng. Educ. Pract. 2011, 137, 51-54. [CrossRef]

10. Wang, S.; Yan, C.; Xiao, F. Quantitative energy performance assessment methods for existing buildings. Energy Build. 2012, 55, 873-888. [CrossRef] 
11. Fumo, N. A review on the basics of building energy estimation. Renew. Sustain. Energy Rev. 2014, 31, 53-60. [CrossRef]

12. Darko, A.; Chan, A.P.C. Critical analysis of green building research trend in construction journals. Habitat Int. 2016, 57, 53-63. [CrossRef]

13. Cambeiro, F.P. Application of newer design and manufacturing techniques in construction for residential architecture: From centimeter to millimeter. Ph.D. Thesis, University of Vigo, Pontevedra, Spain, 2013. Available online: http:/ / hdl.handle.net/11093/230 (accessed on 28 February 2017). (In Spanish)

14. Wong, K.; Fan, Q. Building information modelling (BIM) for sustainable building design. Facilities 2013, 31 , 138-157. [CrossRef]

15. Ghassemi, R.; Becerik-Gerber, B. Transitioning to Integrated Project Delivery: Potential barriers and lessons learned. Lean Constr. J. 2011, 32-52.

16. Khaddaj, M.; Srour, I. Using BIM to retrofit existing buildings. Procedia Eng. 2016, 145, 1526-1533. [CrossRef]

17. Huber, D.; Akinci, B.; Oliver, A.A.; Anil, E.; Okorn, B.E.; Xiong, X. Methods for automatically modeling and representing as-built building information models. In Proceedings of the NSF CMMI Research Innovation Conference, Atlanta, GA, USA, 4-7 January 2011.

18. El-Omari, S.; Moselhi, O. Integrating 3D laser scanning and photogrammetry for progress measurement of construction work. Autom. Constr. 2008, 18, 1-9. [CrossRef]

19. Brenner, C. Building reconstruction from images and laser scanning. Int. J. Appl. Earth Obs. Geoinf. 2005, 6, 187-198. [CrossRef]

20. Wang, J.; Li, S.; Wang, X.; Mao, C.; Guo, J. The application of BIM-enabled facility management system in complex building. Int. J. 3-D Inf. Model. 2013, 2, 16-33. [CrossRef]

21. Zlot, R.; Bosse, M.; Greenop, K.; Jarzab, Z.; Juckes, E.; Roberts, J. Efficiently capturing large, complex cultural heritage sites with a handheld mobile 3D laser mapping system. J. Cult. Herit. 2014, 15, 670-678. [CrossRef]

22. Vosselman, G. Design of an indoor mapping system using three 2D laser scanners and 6 DOF SLAM. ISPRS Ann. Photogramm. Remote Sens. Spatial Inf. Sci. 2014, II-3, 173-179. [CrossRef]

23. Borrmann, D.; Nüchter, A.; Dakulović, M.; Maurović, I.; Petrović, I.; Osmanković, D.; Velagić, J. A mobile robot based system for fully automated thermal 3D mapping. Adv. Eng. Inform. 2014, 28, 425-440. [CrossRef]

24. Fox, M.; Coley, D.; Goodhew, S.; Wilde, P. Thermography methodologies for detecting energy related building defects. Renew. Sustain. Energy Rev. 2014, 40, 296-310. [CrossRef]

25. Picco, M.; Marengo, M. On the impact of simplifications on building energy simulation for early stage building design. J. Eng. Archit. 2015, 3, 66-78. [CrossRef]

26. Markiewicz, P. Modern analysis and simulation tools and skills for the evaluation and design of urban projects. In Proceedings of the International Conference Virtual City and Territory-11th Congress Virtual City and Territory, Krakow, Poland, 6-8 July 2016; Centre of Land Policy and Valuations (CPSV): Barcelona, Spain, 2016; pp. 1028-1039.

27. Holness, G.V.R. BIM gaining momentum. ASHRAE J. 2008, 50, $28-40$.

28. The Construction Industry Institute. Available online: https://www.construction-institute.org (accessed on 2 March 2017).

29. Yang, Z.; Becerik-Gerber, B. Coupling occupancy information with HVAC energy simulation: A systematic review of simulation programs. In Proceedings of the 2014 Winter Simulation Conference, Savannah, GA, USA, 7-10 December 2014; pp. 3212-3223.

30. Zeng, R.; Chini, A.; Srinivasan, R.S.; Jiang, P. Energy efficiency of smart windows made of photonic crystal. Int. J. Constr. Manag. 2017, 17, 100-112. [CrossRef]

31. Atam, E. Current software barriers to advanced model-based control design for energy-efficient buildings. Renew. Sustain. Energy Rev. 2017, 73, 1031-1040. [CrossRef]

32. García-Alvarado, R.; González, A.; Bustamante, W.; Bobadilla, A.; Muñoz, C. Características relevantes de la simulación energética de viviendas unifamiliares. Inf. Constr. 2014, 66. [CrossRef]

33. Wang, X.; Kendrick, C.; Ogden, R.; Walliman, N.; Baiche, B. A case study on energy consumption and overheating for a UK industrial building with rooflights. Appl. Energy 2013, 104, 337-344. [CrossRef]

34. Sacht, H.M.; Bragança, L.; Almeida, M.G. Facades modules for eco-efficient refurbishment of buildings: An overview. In Proceedings of the Conference Portugal SB10: Sustainable Building Affordable to All, Vilamoura, Portugal, 17-19 March 2010; Universidade do Minho: Braga, Portugal, 2010; pp. 423-432. 
35. Crawley, D.B.; Hand, J.W.; Kummert, M.; Griffith, B.T. Contrasting the Capabilities of Building Energy Simulation Software Tools. 2005. Available online: https://pure.strath.ac.uk/portal/files/253952/ strathprints006555.pdf (accessed on 16 March 2017).

36. Sousa, J. Energy simulation software for buildings: Review and comparison. In Proceedings of the International Workshop on Information Technology for Energy Applications (IT4ENERGY 2012), Lisbon, Portugal, 6-7 September 2012. Available online: http://ceur-ws.org/Vol-923/paper08.pdf (accessed on 2 February 2017).

37. Crawley, D.B.; Lawrie, L.K.; Winkelmann, F.C.; Buhl, W.F.; Huang, Y.J.; Pedersen, C.O.; Strand, R.K.; Liesen, R.J.; Fisher, D.E.; Witte, M.J.; et al. EnergyPlus: Creating a new-generation building energy simulation program. Energy Build. 2001, 33, 319-331. [CrossRef]

38. Prada-Hernández, A.V.; Rojas-Quintero, J.S.; Vallejo-Borda, J.A.; Ponz-Tienda, J.L. Interoperability of building energy modeling (BEM) with building information modeling (BIM). In Proceedings of the SIBRAGEC ELAGEC 2015, São Carlos, Brasil, 7-9 October 2015; pp. 519-526.

39. Jalaei, F.; Jrade, A. Integrating BIM with green building certification system, energy analysis and cost estimating tools to conceptually design sustainable buildings. In Proceedings of the Construction Research Congress 2014, Atlanta, GA, USA, 19-21 May 2014; pp. 140-149.

40. Choi, J.; Shin, J.; Kim, M.; Kim, I. Development of openBIM-based energy analysis software to improve the interoperability of energy performance assessment. Autom. Constr. 2016, 72, 52-64. [CrossRef]

41. Gourlis, G.; Kovacic, I. A study on building performance analysis for energy retrofit of existing industrial facilities. Appl. Energy 2016, 184, 1389-1399. [CrossRef]

42. Ilter, D.; Ergen, E. BIM for building refurbishment and maintenance: Current status and research directions. Struct. Surv. 2015, 33, 228-256. [CrossRef]

43. International Organization for Standardization (ISO). ISO 16739_Industry Foundation Classes (IFC) for Data Sharing in the Construction and Facility Management Industries 2013; ISO: Geneva, Switzerland, 2013.

44. Gourlis, G.; Kovacic, I. Building Information Modelling for analysis of energy efficient industrial buildings-A case study. Renew. Sustain. Energy Rev. 2017, 68, 953-963. [CrossRef]

45. Jeong, W.; Son, J. An algorithm to translate building topology in building information modeling into object-oriented physical modeling-based building energy modeling. Energies 2016, 9. [CrossRef]

46. Chalmers, P. Climate Change: Implications for Buildings. Key Findings from the Intergovernmental Panel on Climate Change (IPCC) 5th Assessment Report; Buildings Performance Institute Europe (BPIE): Brussels, Belgium, 2014. Available online: https://www.bmz.de/en/publications/topics/climate/Buildings_Briefing_Web_EN_ Pages.pdf (accessed on 1 March 2017).

47. Spyridaki, N.A.; Ioannou, A.; Flamos, A.; Oikonomou, V. An ex-post assessment of the regulation on the energy performance of buildings in Greece and the Netherlands-A cross-country comparison. Energy Effic. 2016, 9, 261-279. [CrossRef]

48. European Commission and Parliament. Directive 2010/31/EU of the European Parliament and of the Council of 19 May 2010 on the Energy Performance of Buildings (EPBD Recast); Eurpean Union: Luxembourg, 2010. Available online: http:/ / eur-lex.europa.eu/legal-content/EN/TXT/PDF/?uri=CELEX:32010L0031\&from= ES (accessed on 22 February 2017).

49. Patiño-Cambeiro, F.; Armesto, J.; Patiño-Barbeito, F.; Bastos, G. Perspectives on near ZEB renovation projects for residential buildings: The Spanish case. Energies 2016, 9. [CrossRef]

50. Burford, N.; Jones, R.; Reynolds, S.; Rodley, D. Macro micro studio: A prototype energy autonomous laboratory. Sustainability 2016, 8. [CrossRef]

51. European Parliament and Council. Commission Delegated Regulation 244/2012 of 16 January 2012 Supplementing Directive 2010/31/EU of the European Parliament and of the Council on the Energy Performance of Buildings by Establishing a Comparative Methodology Framework for Calculating Cost-Optimal Levels of Minimum Energy Performance Requirements for Buildings and Building Elements. European Union: Luxembourg, 2012. Available online: http://eur-lex.europa.eu/legal-content/EN/TXT/ PDF/?uri=CELEX:32012R0244\&from=en (accessed on 26 February 2017).

52. European Parliament and Council. Directive 2012/27/EU of The European Parliament and of the Council of 25 October 2012 on Energy Efficiency, Amending Directives 2009/125/EC and 2010/30/EU and Repealing Directives 2004/8/EC and 2006/32/EC; European Union: Luxembourg, 2012. Available online: http:/ /eur-lex.europa.eu/ legal-content/EN/TXT/PDF/?uri=CELEX:32012L0027\&from=ES (accessed on 21 February 2017). 
53. Ministry of the Presidency of Spain. Royal Decree 235/2013 on the basic procedure for energy performance certification in buildings. Boletín Oficial del Estado 2013, 89, 1-14. (In Spanish)

54. Ministry of Public Works of Spain. Basic Document HE of the Spanish Technical Building Code (CTE-DB-HE). Available online: https://www.codigotecnico.org/images/stories/pdf/ahorroEnergia/ DccHE.pdf (accessed on 6 March 2017). (In Spanish)

55. Ministry of the Presidency of Spain. Royal Decree 1027/2007-Spanish Regulation on Thermal Systems in Buildings (RITE). Boletín Oficial del Estado 2007, 207, 35931-35984. (In Spanish)

56. Ministry of Industry, Energy and Tourism of Spain. Royal Decree 56/2016, which transposes the Directive 2012/27/UE on energy efficiency, as regards energy audits, accreditation of service suppliers and energy auditors, and the promotion of efficiency in the supply of energy. Boletín Oficial del Estado 2016, 38, 11655-11681. (In Spanish)

57. Ministry of Industry, Energy and Tourism of Spain. Certification of Energy Efficiency: Registration of Authorized Documents. Available online: http://www.minetad.gob.es/energia/desarrollo/EficienciaEnergetica/ CertificacionEnergetica/DocumentosReconocidos/Paginas/documentosreconocidos.aspx (accessed on 9 March 2017). (In Spanish)

58. ECOEFYS. Energy Efficiency Certification Software CE3X for Existing Buildings. Available online: http://www. ecoefys.com/programa-ce3x-de-certificacion-energetica-edificios-existentes (accessed on 13 February 2016). (In Spanish)

59. Institute for Energy Diversification and Savings (IDAE). IDAE Guide: Technical Background Manual on Energy Efficiency Certification for Existing Buildings CE3X; IDAE: Madrid, Spain, 2012. Available online: http://www.minetad.gob.es/energia/desarrollo/EficienciaEnergetica/CertificacionEnergetica/ DocumentosReconocidos/Documents/Manual_fundamentos_tecnicos_CE3X_05.pdf (accessed on 15 March 2017). (In Spanish)

60. Builidngs Performance Institute Europe (BPIE). Energy Performance Certificates across the EU; BPIE: Brussels, Belgium, 2014. Available online: http://bpie.eu/wp-content/uploads/2015/10/Energy-PerformanceCertificates-EPC-across-the-EU.-A-mapping-of-national-approaches-2014.pdf (accessed on 3 May 2017).

61. European Parliament and Council. Directive 2014/24/EU of 26 February 2014 on Public Procurement and Directive Repealing 2004/18/EC; European Union: Luxembourg, 2014. Available online: http:/ /eur-lex.europa.eu/ legal-content/EN/TXT/PDF/?uri=CELEX:32014L0024\&from=ES (accessed on 23 February 2017).

62. Liz, J.T. BIM, el Futuro de las Infraestructuras. Available online: http://www.esbim.es/wpcontent/uploads/2016/06/esBIM-Jorge-Torrico-Comision-esBIM-futuro-infraestructuras.pdf (accessed on 8 March 2017). (In Spanish)

63. Presidency of the Government of Spain. Royal Decree 2429/1979-Basic Building Regulation NBE-CT-79, on thermal requirements for buildings. Boletín Oficial del Estado 1979, 253, 24524-24550. (In Spanish)

64. Armesto, J.; Sánchez-Villanueva, C.; Patiño-Cambeiro, F.; Patiño-Barbeito, F. Indoor multi-sensor acquisition system for projects on energy renovation of buildings. Sensors 2016, 16. [CrossRef] [PubMed]

65. The Qt Company. Available online: https://www.qt.io (accessed on 4 May 2017).

66. Abanda, F.H.; Vidalakis, C.; Oti, A.H.; Tah, J.H.M. A critical analysis of Building Information Modelling systems used in construction projects. Adv. Eng. Softw. 2015, 90, 183-201. [CrossRef]

67. Instituto Eduardo Torroja de Ciencias de la Construcción; CEPCO; AICIA. Catálogo de Elementos Constructivos del CTE; CSIC: Madrid, Spain, 2010. Available online: http:/ /www.anape.es/pdf/Catalogo $\% 20 \mathrm{de} \% 20 \mathrm{Elementos} \%$ 20Constructivos\%20CAT-EC-v06.3_marzo_10.pdf (accessed on 16 February 2017). (In Spanish)

68. Ministry of Industry, Energy and Tourism of Spain. RITE: Authorized documents. Available online: http:/ / www.minetad.gob.es/energia/desarrollo/EficienciaEnergetica/RITE/Reconocidos/Paginas / IndexDocumentosReconocidos.aspx (accessed on 1 March 2017). (In Spanish)

69. Association for Research and Industrial Cooperation of Andalusia (AICIA). Classification of the Energy Performance. Existing Buildings; Ministry of Public Works of Spain: Madrid, Spain, 2011; (In Spanish).

70. Aurea Consulting. Infiltrations in Accordance with CTE. Available online: https://ecoeficiente.es/ infiltracioneshe (accessed on 7 March 2017). (In Spanish)

(C) 2017 by the authors. Licensee MDPI, Basel, Switzerland. This article is an open access article distributed under the terms and conditions of the Creative Commons Attribution (CC BY) license (http://creativecommons.org/licenses/by/4.0/). 